\title{
PROMOTING DESIGN THINKING AS A TECHNIQUE ON TEACHING SPEAKING SKILL
}

Siti Sa'diah, Endah Novita \& Nur Latifah

Universitas Muhammadiyah Tangerang

\begin{abstract}
Speaking in English as a foreign language is highly complex and challenging skill for Indonesian students. It requires grammar, pronunciation, and vocabulary mastery. It also needs students' confidence to be brave to share their ideas. This study attempted to promote design thinking that can be used on teaching speaking in order to stimulate the teachers to try to apply this technique on their teaching and to enhance their students' speaking skill. In order to reach the objective of the study, the qualitative approach was used. Based on the analysis, it showed that the design thinking technique guides gradually the students to overcome the problem situationally and contextually by understanding, observing, pointing view, ideating, prototyping, and testing all ideas related to the problem in order to get the distintive and creative solution. In other words, the students are directed to think critically and brave to share their thoughts in a spoken language. So, the students can get more chance to speak them up and it, certainly, can help the students to increase their speaking skill.
\end{abstract}

Keywords: Speaking skill, Teaching speaking, Design thinking

\section{A. INTRODUCTION}

\section{Background}

Speaking is considered as one of the most problems faced by English students in Indonesia. They seem really hard to produce sentences in English eventhough they have got an English subject for a long period of time, from elementary school to university level. This problem is due to the fact that they are not confident to share what they thought in a spoken language. They prefer to write it down or keep silent during the learning process. This could be one of the impacts of teacher-centered learning process in which the teacher fully controls all the activities in the 
classroom, the teacher talks a lot while the students listen to her/him, and the students are quiet and put all of their focus on the teacher. In other words, the teacher-centered learning process does not encourage the students to be more involved during the learning process in the classroom.

The other problem faced by the students on speaking skill is related to pronunciation. When they hear an English word, it seems too difficult to produce. They are not familiar and accustomed to pronouncing it since it has quiet different rule with their native language. However, they should understand both the written and spoken form in order to understand English so that their can communicate their thought well. In addition, they are lack of vocabulary. They are seldom to look up dictionary when they get difficult words and lack practice when they get new words. They also do not concern on memorizing the vocabulary so eventhough they meet the English subject in every level during the school, they still get difficulty in producing sentences.

Furthermore, the students are afraid of making mistakes. This happens due to their poor mastery on grammar. They are still confused on constructing gramatically correct sentences. They often think what tenses or other grammatical rules should be used before they speak up. These make them passive in classroom. However, mastering grammar is required to avoid misunderstanding of messages that are being conveyed.

The problem also appears on very little time to practice English spoken language. During the learning process, the students mostly do exercises of speaking task in the form of wrtitten task. They are really seldom to practice their spoken language. They are not much facilitated with the activities involved speaking skill. The most frequent speaking activity conducted in the classroom is practicing a model dialog. In this case, the role of the teacher is very needed in order to create various activities to facilitate the students to have more time in practicing their spoken language so that they will be more active in the classroom.

In line with the last problem, the way teachers teach their students give into account to the students' mastery in speaking skill. The teachers should vary their teaching techniques or strategies to cover the speaking skill. In other words, the 
teachers should select appropriate and applicable techniques or methods before starting the teaching process, espeacially in speaking skill. So, the learning process will not be monotonous and can engange the students in all activities. In addition, the teacher should start themselves delivering the lessons in English mostly or entirely. This can be another exposure for the students in the case of developing speaking skill. The teachers can be a real model and, of course, a partner for their students to practice the spoken language. Besides, the teachers are confidently able to encourage their students to speak in English since they have applied it in their own teaching. However, as a matter of fact most English teachers use Bahasa (read Indonesian language) during the teaching process. In this case, the students' understanding of the materials and the target of certain criteria are assumed to be the classical reasons. They think that the materials are not successfully undesrtood by the students if they use English as the main instructional language. When it happens, the objective of the lesson absolutely cannot be achieved.

Concerning the problems described previously, one of the ways that can be done is to modify the teaching and learning process by using the suitable techniques. Therefore, this paper attempted to promote one of the techniques, namely Design Thinking, on teaching speaking skill. Although the technique is applicable in language teaching, only few papers discussed it. So, this paper tried to fill that gap.

According to IDEO (2012), design thinking is a mind-set,"it is about believing we can make a difference and having interactional process in order to get new, relevant solutions that create positive impact" (p.11). In other hand, design thinking is generally defined as a process to develop one's confidence and creativity to make possitive effect.

Regarding to the education field, design thinking is usually referred to "design-based learning" seen as a model to build up creativity, endurance, engagement, and innovation (Efeoglu, Moller, Boer, 2014). It can be said that design thinking teaches the students to think widely. They should think creatively to generate solution. They are required to think critically and reason logically to solve a 
complex problem. They are able to explore their ideas toward process and get the product as a result through application of particular form of thinking.

Furthermore, there are seven principles and six phases in conducting the design thinking technique. Both of them are actually interrelated. The principles are as a foundation in order to make the technique sturdy and the phases of process are used as an operational guideline of the principles. Here is detailed description of the principles and procedures of design thinking.

Lande (2010) states there are seven basic principles of design thinking. The first is a human-centred process. It focuses on how to make people as the source of inspiration and direction to overcome design challenges. The second is mindful process in which it requires a critical mindset to have metacognitive awareness. The third is empathy. It is the intellectual identification with or various experiencing of the feelings, thoughts, or attitude of others. It develops through a process 'need finding' in which one focuses on discovering people's explicit and implicit needs. The fourth is culture of prototyping. The mind-set of creating and maintaining a culture of prototyping focuses on being highly experimental, building to think, and engaging people with artefacts. The fifth is show don't tell me. It takes traditional visualization one step further, as it includes sketching and traditional prototyping, digital communication and storytelling. The sixth is bias toward action focusing on actionoriented behaviour rather than discussion based work. A bias toward action mindset utilizes all modalities of learning. The last is radical collaboration. It is built upon idea than radically diverse multidisciplinary team will lead to greater innovations of teams that come from the same discipline. Examining and confronting team dynamics is an essential component of radical collaboration. In short, these principles are as a set of main roles in conducting design thinking technique.

Beside those priciples, applying the technique should also consider six components of design thinking process as proposed by Brown (2012). Here is detail description of the six components.

1) Understand

The first phases of design thinking process is understand. During this phase, students immerse themselves in learning about issues related to the 
design challenge. They access a wide array of resources that include conversations with experts, viewing multimedia, and conducting research. The goal is to develop background knowledge. They use their developing understanding as a springboard as they begin to address their design challenge.

\section{2) Observe}

Students become keen people watchers in the observation phase of design thinking process. They watch how people behave and interact. They talk to people about they are doing, ask questions, and reflect on what they see. The understanding and observing phases of design thinking help students develop a sense of empathy. In this phase of design thinking, the focus is on becoming aware of people's needs and development.

3) Point of View

In the design thinking process, one must develop a point of view that is based on a specific user statements framed as "How might we ...?" questions. Students must synthesize what they learned in the understanding and observing phases. A point of view statement takes into account information about user's needs and insight. The formulation for point of view is: User + Need + Insight $=$ point of view statement. For example, a student might have interviewed a classmate who said "I hate doing homework because it takes me forever to finish". A point of view might be "How might we create a way for this student to do his or her homework more efficiently?" an effective point of view statement is one that can be answered in a multitude of ways.

4) Ideate

In the ideation phase, quantity is encouraged. Brainstorming ideas is the foundation of this phase, and students may be asked to generate a hundred ideas in a single session. Students are asked to deter judgment of other's ideas. Every idea that is suggested is recorded. A supportive classroom climate is essential. Students are challenged to become silly, savvy, risk takers, wishful thinkers and dreamers of the impossible and the possible ones. They work on 
their design challenges with openness to unexpected ideas and new possibilities as a team where everyone contributes and builds on other's ideas.

5) Prototype

Prototyping is a rough and rapid portion of the design process. A prototype can be a sketch, model, or a cardboard box. It is a way to convey an idea quickly; the more one produces the more one can learn. A diverse assortment of material is provided to use when one creates prototype, and every prototype is created with the purpose to learn something specific by testing it. It is better to fail early and often as one created prototype.

6) Test

Testing is part of an iterative process that provides feedback. The purpose of testing is to learn what works and what doesn't, and then iterate. This means going back to one's prototype and modifying it based on feedback. It means that by doing testing, it can be known the parts that have been reached successfully and the parts that have not.

In addition, the understanding phase is also called by defining. In this phase, the students should work in a group and discuss their knowledge of the specific issue. By working in a group, the students are able to elicit their friends's knowledge since every student has a chance to express his/her knowledge. During this phase, the students are allowed to gather ideas from any resources in order to build up their background knowledge about the issue. This phase provides the students to be enganged in the learning process.

Observing, as the second phase of the design thinking technique, means "Watch real people in real-life situations to find out how they work, what confuses them, what they like and dislike, and where their needs can be better served" (Noweski et al , 2008, p. 45). In other words, this phase aims to broaden the information that the students have got in the first phase and to make it clear as a stand point about what they are going to deal with. This phase also prepares the students to get ready to ideate phase.

In the third phase, making point of view phase, the students make a formulation "How might that problem become crucial in people's life?". The following 
phase is ideating. In this phase, the ideas collected are generated and organized (Harris and Ambrose, 2010). The students are invited to accept possible ideas so IDEO (2012) claims that in this phase, the students can have brainstorming. Then, they might discuss the answer to generate the ideas in order to get the prototype, which belong to the fourth phase, of solutions. The solutions gained can be tested eventually to get feedback.

Furthermore, some researches focusing on design thinking as a teaching technique have been conducted. They are commonly presented in the form of quasi-experimental method. In this case, design thinking is used as a teatment that will be applied in an experimetal class in order to get empirical data if the technique can increase or decrease the students' achievement in a certain focus.

One of the researches was conducted by Anderson, N., Timms, C., and Hajhashemi, K. (2014) entitled "Improving Online Learning through the Use of Design Thinking at Australian University". Two objectives were targeted in this study. First, the students could successfully use design thinking technique to improve their design of online learning activities for school-based students. Second, university instructors could successfully use design thinking to improve online university subject design. In this study, the researchers conducted a mixed-method including participatory observation and semi-structured interviews about academics perceptions of design thinking. The result showed that there were advantages on the use of design thinking on online learning. The design thinking could direct students from a predominantly analytical approach to examining existing models of online learning activities to an approach emphasizing synthesis, creation, innovation, and empathy.

Another research discussing design thinking was conducted by Fatima Zohra Rahmani (2016) with the title "The Effect of Design Thinking as Pre-writing Strategy Paragraphs at Mohamed Kheider University". The objective of this study is to investigate the effectiveness of the design thinking as a pre-writing strategy paragraphs at Mohamed Kheider University. In this study, the researcher used quasi-experimental research design with the use of non-equivalent control group class. It is appropriate with the aims of the research that is to measure the objective 
of the data through conceptual variable and the data gained are presented into statistical analysis. In her research, she concluded that there was a significant difference between the students who were taught by using design thinking and those who were taught by using conventional method. In the other words, the use of design thinking on teaching writing is better than the use of conventional method.

By considering the speaking problems faced by both the students and the teachers, this paper aims to to promote design thinking that can be used on teaching speaking in order to stimulate the teachers to try to apply this technique on their teaching and to enhance their students' speaking skill. Besides, this paper can fulfill the gap in the term of analyzing design thinking with qualitative approach.

\section{Methodology}

This paper presents a detailed description of utilizing design thinking as a technique which can be applied on teaching speaking skill. The paper describes the theory of design thinking, then, synthesize it in order to get the advantages of applying the technique on teaching speaking skill. Therefore, the study uses qualitative approach. As stated by Cresswell (2008), a qualitative research is oriented on description and exploration of certain phenomena or life issues. Then, the method used in this study is qualitative descriptive.

\section{B. RESULT AND DISCUSSION}

Concerning the seven principles and the six procedures of design thinking, the teachers are assumed to be able to enhance their teaching and learning outcome. In the case of teaching speaking skill, design thinking provides the students huge opportunities to practice their spoken language during the learning process. It is reflected on all stages of design thinking in which the students should discuss the specific issue in order to get the solution.

Other advantage of conducting design thinking in the classroom, especially on teaching speaking is that it can stimulate the students to boost their confidence. It is trained started from the fist phase in which the students are put in goups and each of them should speak up their schemata of the issue that is being discussed. 
Here, the students are motivated to practice in small audience involving the group members firstly and in larger audience involving the entire of the class member eventually.

Furthermore, design thinking provokes the students to think critically and creatively. The students should dig as many informations as possible among the group members' knowledge, then, they combine, select, and organize them and try to relate them with the real life so that they can get the distinctive or critical point of view which has good impact. In line with this advantage, Barseghian (2009) conveys that design thinking implication to education provides a process dealing with student's creativity, and enhance them to explore subject problem and analyze it to depict its specification. In addition as claimed by Kwek (2011), design thinking guides to get better ideas due to the fact that it can encourage the perpetual deconstruction and building of thoughts that are formerly regarded as static. In this case, the students are trained to be brave to take risk and involve in encountering problems. Therefore, this technique helps the students to design better solutions to the problems which is being discussed.

During the design thinking process, the students should immerse themselves in the learning process. So, they can feel the learning experience and may motivate the students to give their best to achieve the successful learning.

Beside the four advantages, the design thinking contribution on teaching speaking skill can be seen from the teacher's side. First, since the students more participate, the learning process is more alive and the learning target can hopefully be achieved. Second, the teachers are motivated not only as the intrusctors but also as models to their students. In other words, it means that if the teachers want their students to mostly speak in English, they have to facilitate their students by delivering the lesson with English during the teaching and learning process. Besides, the teachers can use English as a medium interaction or an instructional language not only inside but also outside the classroom. So, they can be good models for their students and the students can have more exposures in a spoken language. 
Furthermore, since design thinking provokes the students to think critically, the teachers have a chance to train themselves and measure their critical thinking. This can be functioned as a feedback for the teachers to run the following teaching process. In short, once the teacher can apply the principles and procedures of design thinking on their teaching speaking skill, the success of learning process could be achieved.

To get deeper application on design thinking, here are the proposed classroom activities which consider the principles and procedures of design thinking applied in teaching speaking skill. The objective of teaching and learning process is that students are able to identify orally the purpose, the generic stuctures, and the language features of the argumentative text and tell environmental problems presented in the text in spoken language. Then, the material given is an argumentative text including the explanation of definition, purpose, generic structures, and language features. There will be equipped by the sample of argumentative text being discussed.

a. Definition

An argumentative text or analytical exposition text tells elaborations of the writer's idea about a certain phenomenon.

b. Purpose

There are two purposes of argumentative text. They are: (a) to persuade readers or listeners that there is something that, certainly, needs to get attention and (b) to persuade readers and listeners that this opinion is correct by supplying some supported arguments.

c. Generic structure

The structure of an argumentative text is divided into four. Those are: (a) thesis introduces the topic and shows speaker or writer's position; outlines of the arguments to be presented, (b) arguments consist of point and its elaboration, stating the main argument, (c) elaboration develops and supports each point of argument, and (d) conclusion refers reiteration (restatement), restates speaker or writer's opinion.

d. Language feature 
An argumentative text fosters three points of language feature. They are: (a) focuses on generic human and non-human participants, (b) needs material processes which is used to state what happens, and (c) uses simple present tense.

e. Argumentative text sample

\section{Is Smoking Good for Us?}

Before we are going to smoke, it is better to look at the facts. About 50 thousand people die every year in Britain as direct result of smoking. This is seven times as many as die in road accidents. Nearly a quarter of smokers die because of diseases caused by smoking.

Ninety percent of lung cancers are caused by smoking. If we smoke five cigarettes a day, we are six times more likely to die of lung cancer than a non-smoker. If we smoke twenty cigarettes a day, the risk is nineteen times greater. Ninety five percent of people who suffer of bronchitis are people who are smoking. Smokers are two and half times more likely to die of heart disease than non-smokers.

Additionally, children of smoker are more likely to develop bronchitis and pneumonia. In one hour in smoky room, non-smoker breathes as much as substance causing cancer as if he had smoked fifteen cigarettes.

Smoking is really good for tobacco companies because they do make much money from smoking habit. Smoking, however is not good for health both the smokers themselves and everybody else.

f. Steps of teaching

There will be three meetings covering the material. Each meeting will be presented in the following description.

First meeting

1. Opening

a. Teacher greets students and checks students' attendance.

b. Teacher gives stimulation to the students.

2. Main activity

1) Exploration

a. Teacher shows a picture of smoking.

b. Teacher asks students "what do you think about this picture?"

c. Teacher chooses some students to give their opinion. 
2) Elaboration

a. Before the learning process begins, teacher shows up an argumentative text like "Is smoking good for us?"

b. Teacher asks the students to read the text and understand the content of the text.

c. Teacher chooses some students to explain the content of the text based on their knowledge.

d. Teacher explains the definition, the purpose of the text, and generic structure of the argumentative text.

e. Teacher gives a chance to students to ask about the material given.

f. Teacher gives the treatment to the students by using design thinking technique. First, the teacher shows a topic of "Is Smoking good for us?" then the teacher asks the students to give their understanding about the topic showed by the teacher. Second, the teacher asks the students to observe why the topic is needed to discuss, after that teacher chooses students to give their arguments related to the topic. Third, teacher chooses some of students to conclude the students' point of view.

3) Confirmation

a. Teacher and students make evaluation of today's material.

4) Closing

a. Teacher asks students to tell a summary of the material that has been discussed.

b. Teacher closes the today's subject by praying together.

\section{Second Meeting}

1. Opening

a. Teacher greets students and checks students' attendance.

b. Teacher conveys the objectives of learning. 
2. Main Activity

1) Exploration

a. Teacher asks students "Can any one of you tell me about the argumentative text?"

b. Teacher gives a chance to students to give the opinion about the argumentative text.

2) Elaboration

a. Teacher reiterates the material of argumentative text.

b. Teacher explains well-the ways to understand the argumentative text.

c. Teacher divides the students to be some groups. Each group consists of six or eight students. It aims to make students to deliver their critical thinking or their point of view of the material.

d. Teacher gives the topic for the students. Students should understand, observe, and give their argument or point of view by using design thinking technique.

e. Teacher asks students to start their discussion in each group.

f. Teacher monitors the discussion.

3) Confirmation

a. Teacher and students make evaluation of today's material.

4) Closing

a. Teacher asks students to make a summary of the argumentative text in a spoken language.

b. Teacher closes the today's subject by praying together.

\section{Third Meeting}

1. Opening

a. Teacher greets students and checks students' attendance.

b. Teacher conveys the objectives of today's learning. 
C. Teacher reviews the previous material.

2. Main activity

5) Exploration

a. Teacher asks students "Please tell me about the argumentative text".

b. Teacher gives a chance to students to give the opinion about what they have understood.

c. Teacher asks students to mention the step how to deliver their point of view of argumentative text.

d. Teacher stimulates students' thinking with give some questions related to the topic given.

6) Elaboration

a. Teacher reiterates the material of argumentative text.

7) Confirmation

a. Teacher and students make evaluation of today's material.

3. Closing

a. Teacher asks students to summarize orally the argumentative text.

b. Teacher closes the today's subject by praying together.

The teaching and learning process using design thinking described in detail previously provides more time for the students to practice their spoken language. They are also trained to be confident to think critically and convey what they think, feel, and know about the specific issue eventually.

\section{CONCLUSION}

Speaking in English as a foreign language in Indonesia has been a complicated and chalengging skill since it requires self confidence and a lot of practice to develop it. In addition, to be fluent in English involves the mastery of language components such as vocabulary, pronunciation, and grammar. However, 
speaking skill has a main role in English learning because it is considered as an international language, mostly used by all people around the world. Therefore, it is necessary to get a technique to solve the problem.

Based on the analysis described previously, design thinking is such an applicable technique that can be used to improve students' speaking skill. It offers creativity, endurance, engagement, and innovation to gain a good solution for the problems they face. Moreover, it helps the students' to build up their confidence to share their ideas, thought, and feeling in the form of spoken language. In other words, the students can have more oppurtunities to practice their speaking skill in the classroom.

Seeing on the teachers' point of view, the technique may motivate the teachers to apply it on their teaching process so that it can indirectly be a scientifical prove that can support or againts the existing theories. It also stimulates the teachers to make the teaching process more various in order to attract the students's attention and provide interactive teaching process. So, they can increase their students' speaking skill.

\section{BIBLIOGRAPHY}

Ambrose, G. \& Harris, P. 1st ed. (2010). Design Thinking. AVA Publishing SA.

Barseghian, T. (2009). Design Thinking: Creative Ways to Solve Problems. In Edutopia.

Creswell, J.W. (2008). Mixed Method Reader. New York: Sage Publication.

Efeoglu, A., Boer, H., Moller, CH. (2013). Design thinking: characterictics and promises. Enschede: Continuous Innovation Network (CINet), 241 - 256. DOI:10.13140/2.1.4737.6642014).

IDEO. 2nd ed. (2012). Design thinking for educators. Retrieved from http://www.designthinkingforeducators.com. 
Kwek, S.H. (2011). Innovation in the Classroom: Design Thinking for 21st Century Learning. (Published Master's Thesis). Retrieved from: http://www. Stanford.edu/group/redlab/cgibin/publications resources.php.

Noweski, $\mathrm{CH}$ et al. (2008). Towards a Paradigm Shift in Education Practice: Developing Twenty-First Century Skills with Design Thinking. HassoPlattner-Institute, Postdam, Germany.

Rahmani, F.Z. (2016). "The Effect of Design Thinking as Pre-writing Strategy Paragraphs at Mohamed Kheider University". 